九州大学学術情報リポジトリ

Kyushu University Institutional Repository

\title{
Convergence of integral and its applications
}

Izaki, Mamoru

Electrical Communication Laboratory, Ministry of Telecommunications

https://doi.org/10.5109/12954

出版情報: 統計数理研究. 5 (1/2)，pp.31-34，1952-09. Research Association of Statistical Sciences

バージョン :

権利関係 : 


\title{
CONVERGENCE OF INTEGRAL AND ITS APPLICATIONS
}

\author{
Mamoru IZAKI \\ (Electrical Communication Laboratory, \\ Ministry of Telecommunications)
}

\section{Introduction}

It is a matter of common knowledge that if $f(t)$ be a continuous function defined over the closed interval $0 \leqq t \leqq l$, the following sum (1) converges to a finite value as $\max \left(t_{k}-t_{k-1}\right) \rightarrow 0$.

$$
S_{(1)}=\sum_{k=1}^{n} f\left(\xi_{k}\right)\left(t_{k}-t_{k-1}\right),
$$

where $t_{0}=0, t_{n}=l$ and $n-1 t$-points are randomly chosen in the interval $0 \leqq t \leqq l$, and $\xi_{k}$ is randomly drawn from the sub-interval $t_{k-1} \leqq \xi_{k} \leqq t_{k}$.

The random variable defined by the sum (1) will converge in probability as merely $n \rightarrow \infty$. We will investigate the aspect of convergence and its applications will be described.

\section{Mean value}

Since the random variables $\left(t_{1}, t_{2}, \cdots, t_{n-1}\right)$ and $\left(\xi_{1}, \xi_{2}, \cdots, \xi_{n}\right)$ are mutually independent and $\left(t_{1}, t_{2}, \cdots, t_{n-1}\right)$ are the order statistics, the mean value of random variable defined by the sum (1) is given by the integral

$$
\begin{aligned}
& \text { (2) } \left.\quad E\left(S_{(1)}\right)=\frac{(n-1) !}{l^{n-1}} \int_{0 \leqq t_{1} \leqq t_{2} \leqq \ldots \leqq t_{n-1} \leqq l} \ldots \ldots \ldots . . . \prod_{k=1}^{n} \int_{t_{k-1}}^{t_{k}} \frac{d \xi_{k}}{t_{k}-t_{k-1}}\right) \\
& \times\left[\sum_{k=1}^{n}\left(t_{k}-t_{k-1}\right) f\left(\xi_{k}\right)\right] d t_{1} d t_{2} \cdots \cdots \cdots d t_{n-1} .
\end{aligned}
$$

This integration is easily performed and its result is given by

$$
E\left(S_{(1)}\right)=\int_{o}^{l} f(t) d t .
$$

This equation shows that the sum (1) is an unbiased estimator.

\section{Variance}

Similary the variance of random variable (1) is given by

$$
\begin{aligned}
& \text { (4) } \quad \operatorname{var} .\left(S_{11}\right)=\frac{(n-1) !}{l^{n-1}} \int_{0 \leqq t_{1} \leqq \ldots \leqq} \ldots \ldots \ldots . . . \int_{t_{n-1} \leqq l} \prod_{k=1}^{n}\left(\int_{t_{k-1}}^{t_{k}} \frac{d \xi_{k}}{t_{k}-t_{k-1}}\right) \\
& \times\left[\sum_{k=1}^{n}\left(t_{k}-t_{k-1}\right)\left\{f\left(\xi_{k}\right)\right\}^{2}+\sum_{i \neq j}\left(t_{i}-t_{i-1}\right)\left(t_{j}-t_{j-1}\right) f\left(\xi_{i}\right) f\left(\xi_{j}\right)\right]
\end{aligned}
$$




$$
\begin{aligned}
& \times d t_{1} d t_{2} \cdots \cdots d t_{n_{k}-1}-\left\{\int_{0}^{l} f(t) d t\right\}^{2} \\
& =\frac{(n-1) !}{l^{n-1}} \int_{0 \leqq t_{1} \leqq \cdots \leqq t_{2-1} \leqq l} \ldots \ldots \ldots \ldots \cdot \sum_{k=1}^{n}\left[\left(t_{k}-t_{k-1}\right) \int_{t_{k-1}}^{t_{k}}\{f(t)\}^{2} d t\right. \\
& \left.-\left\{\int_{t_{k-1}}^{t k} f(t) d t\right\}^{2}\right] d t_{1} d t_{2} \cdots \cdots d t_{n-1},
\end{aligned}
$$

but in this case, under the condition that $f(t)$ is continuous, it is difficult that the integral is led to a simple formula. But if $f(t)$ be differentiable, we shall have

$$
\operatorname{var} .\left(S_{(\mathrm{N})}\right)=2\left\{\frac{1}{l} \int_{0}^{l}\left(\frac{d f}{d t}\right)^{2} d t\right\} \frac{l}{\left(\frac{n}{l}\right)^{3}}+O\left(\frac{1}{n^{4}}\right) .
$$

Hence the variance of random variable (1) is proportional to the average of square of tangent of the function $f(t)$ and the length of interval $l$, and inversely proportional to the cube of number of the divided strata per unit length.

\section{A special case}

Here, we will consider a special case such that the interval $0 \leqq t \leqq l$ is divided into $n$ strata of the equal length $l / n$ by $t_{k}(k=1,2, \cdots \cdots, n-1)$. A sample $\left(\xi_{1}, \xi_{2}, \cdots \cdots, \xi_{n}\right)$ is such that each $\xi_{k}$ is randomly drawn from the sub-interval $(k-1) \frac{l}{n} \leqq t \leqq k \frac{l}{n}$. Thus we shall have the finite sum of the following form corresponding to the equation (1)

$$
S_{(2)}=\frac{l}{n} \sum_{k=1}^{n} f\left(\xi_{k}\right) \text {. }
$$

Also in this case, its mean value is the unbiased estimator ${ }^{(1)}$, and when $f(t)$ be differentiable, then the variance is given by

$$
\operatorname{var} .\left(S_{(2)}\right)=\frac{1}{12}\left\{\frac{1}{l} \int_{0}^{l}\left(\frac{d f}{d t}\right)^{2} d t\right\} \frac{l}{\left(\frac{l}{n}\right)^{3}}+O\left(\frac{1}{n^{5}}\right) \text {. }
$$

It is worthly of notice that the equations (7) and (5) are the similar formula.

\section{Some applications}

The errors in the integrator, correlator etc. will be estimated by the results of $(3),(5)$ etc. and this paper deals with integrator which was just made at our laboratory. The integration by this computor is carried out in such a way that the integrand is substituted by a step function, hence 
it appears that the integration is just the evaluation of the $S_{(1)}$ (eq. (1)), but strictly speaking, the calculation is performed in such a way that the point $t$ is drawn sequentially, so it should be treated as process. If the random variable $t$ is Poisson's process, we shall have the same formulae with eq. (3) and (5) as follows.

Since $t$ is the Poisson's process, we shall have

$$
P_{r}\left(t_{k} \leqq t_{k} \leqq t_{k}+d t_{k} \mid t_{k-1}\right)=a e^{-a\left(t_{k}-t_{k-1}\right)} d t_{k},
$$

where $a$ is the mean value of the points taken in a unit length. When a sample $\left(t_{1}, t_{2}, \cdots \cdots, t_{n-1}\right)$ was taken in the interval $0 \leqq t \leqq l$ and $t^{\prime}{ }_{n}$ in the interval $l \leqq t^{\prime} \leqq \infty$, the integration is performed.

While, it may be permissible that $\xi$ is mutually independent of $t$ in our case.

Thus we shall have the following equation corresponding to equation (2)

$$
\begin{aligned}
& a^{n} \int_{0 \leqq t_{1} \leqq \ldots \leqq t_{n-1} \leqq 1 \leqq t_{n}^{\prime}<\infty} \ldots \ldots \ldots \ldots \ldots \ldots \\
& \times\left[\sum_{k=1}^{n}\left(t_{k}-t_{k-1}\right) f\left(\xi_{k}\right)\right] d t_{1} d t_{2} \cdots \cdots d t_{n-1} d t^{\prime}{ }_{n} .
\end{aligned}
$$

And by comparison with equation (8) and (2), we shall easily have

$$
\frac{(a l)^{n-1}}{(n-1) !} e^{-a l} \int_{0}^{l} f(t) d t,
$$

but in this case we must treat so as $n$ is a random variable, then the mean value is

$$
\begin{aligned}
E\left(S_{(1)}\right) & =\sum_{n=1}^{\infty} \frac{(a l)^{n-1}}{(n-1) !} e^{-a l} \int_{0}^{l} f(t) d t \\
& =\int_{0}^{l} f(t) d t .
\end{aligned}
$$

Simiraly, if the integrand $f(t)$ be differentiable, we shall have

$$
\text { (11) } \begin{aligned}
\operatorname{var}\left(S_{\mathrm{(1)}}\right) & =2\left\{\frac{1}{l} \int_{0}^{l}\left(\frac{d f}{d t}\right)^{2} d t\right\} l^{4} \sum_{n=1}^{\infty} \frac{1}{n^{3}} \frac{(a l)^{n-1}}{(n-1) !} e^{-a l}+O\left(\frac{1}{n^{4}}\right) \\
& \equiv 2\left\{\frac{1}{l} \int_{0}^{l}\left(\frac{d f}{d t}\right)^{2} d t\right\} l^{4} E\left[\left(\frac{1}{n+1}\right)^{3}\right]+O\left(\frac{1}{n^{4}}\right),
\end{aligned}
$$

and since we can estimate the value of \{\} in the equation (11) by an appropriate expedient, the estimation of error in the integrator will be performed numerically. 


\section{References}

(1) Tosio Kitagawa: Random Integrations, Bull. Math. Stat. Vol. 4, No. $1 \sim 2$, (1950).

Added in proof: To prove (5) and (7), we have assumed that $f(t)$ be analytic in $0 \leq t \leq l$, and expansible in a power series of $\mathrm{t}$ whose convergence-radius $R$ is greater than $l$ :

$$
f(t)=\sum_{k=0}^{\infty} a_{n} t^{n}, \quad|t|<R .
$$

